\title{
A study of the current status of non-utilization of the book borrowing facility at the Kandy and Matara Regional Centres of the OUSL
}

\author{
D Gunasekera \\ Library, the Open University of Sri Lanka
}

Distance learners engage in self-study with limited face to face contacts. Library support services are one of the most important support services that are provided for distance learners by the Institution. This study investigates the usage of the borrowing facility by the distance learners of the Kandy and Matara Regional Centres (KRC and MRC). The study reveals the characteristics of the borrowing facility users and the reasons for obtaining/not obtaining library membership at their regional centre libraries. This study also reveals the problems faced by the learners in using the book borrowing facility and the promotion of these facilities by the regional centre libraries. Further, the study also investigates the information seeking behavior of distance learners who registered at the two regional centres.

\section{Context}

The Open University of Sri Lanka (OUSL) was established in 1980 and is one of the fifteen state-owned universities functioning under the Universities Act No. 16 of 1978. It is the only national university which offers study programmes through Open and Distance Learning (ODL).

Since, the OUSL is a single mode ODL university; it differs in its vision, mission, goals and teaching strategies from other conventional universities. The OUSL offers study programmes from the certificate through to the diploma level, and from the degree through to the $\mathrm{PhD}$ level in the four different disciplines of education, engineering technology, humanities and social sciences and the natural sciences. There are four regional centres and 22 study centres located across the country.

No formal qualifications are required to register for certificate programmes. Learners who do not wish to register for a regular programme are given an opportunity to follow stand-alone courses in certain specified disciplines. 
The OUSL adopts a multi-mode study system which uses print, audiovisual and online material. Different support systems are provided for each type of material used.

Each course includes several assignments which should be submitted at the end of the course. Assignments consist of questions, exercises and projects which cover the course content. There is also a recommended reading list for each course. Learners are encouraged to use this as reference material. In any ODL institution the facilities provided by the institution's library is considered to be an important aspect of student support services. Hence, it is important to investigate the usage of library facilities available at regional centre libraries in order to enhance the services at the regional centres.

The borrowing facility was introduced to the Kandy Regional Centre (KRC) and Matara Regional Centre (MRC) learners in 1999 giving them more opportunities to access required information. However, Table 1 shows that only a very few have used this facility.

Table 1: Registered learners and library membership 2006-2008

\begin{tabular}{|c|c|c|c|c|c|c|c|c|c|c|c|c|}
\hline & \multicolumn{4}{|c|}{2006} & \multicolumn{4}{|c|}{2007} & \multicolumn{4}{|c|}{2008} \\
\hline & \multicolumn{2}{|c|}{ KRC } & \multicolumn{2}{|c|}{ MRC } & \multicolumn{2}{|c|}{ KRC } & \multicolumn{2}{|c|}{ MRC } & \multicolumn{2}{|c|}{ KRC } & \multicolumn{2}{|c|}{ MRC } \\
\hline $\begin{array}{l}\text { Registered } \\
\text { Learners }\end{array}$ & \multicolumn{2}{|c|}{2061} & \multicolumn{2}{|c|}{819} & \multicolumn{2}{|c|}{2286} & \multicolumn{2}{|c|}{951} & \multicolumn{2}{|c|}{2623} & \multicolumn{2}{|l|}{898} \\
\hline $\begin{array}{l}\text { Library } \\
\text { membership }\end{array}$ & 77 & $3.73 \%$ & 62 & $7.5 \%$ & 92 & $4.02 \%$ & 67 & $7.04 \%$ & 107 & $4.07 \%$ & 100 & $11.13 \%$ \\
\hline
\end{tabular}

The Table 1 shows the number of registered learners at both centres and the percentage of learners who obtained library membership during the three year period 2006 to 2008 . The statistics clearly show that very few learners have taken the library membership even though this facility has been made available to them.

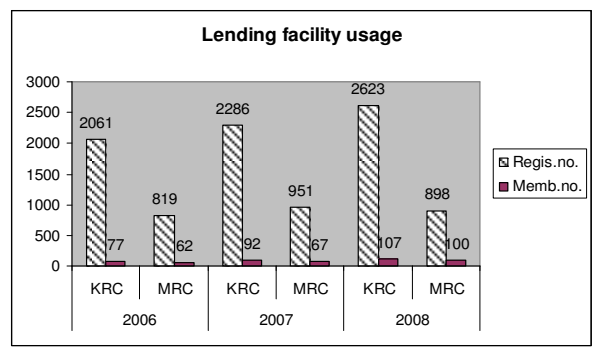

Figure 1: Registered learners and library membership 2006-2008 
Figure 1, clearly shows that a minority of learners used the book borrowing facility during these three years when compared to the total registered student number.

Students' requests and the findings of the earlier research studies (Lekamge et al., 1999; Gunasekera, 2000) were taken into consideration when reducing the membership fee by $50 \%$ (from Rs. 1000.00 to Rs. 500.00). The library fine imposed on learners was also reduced from Rs. 50.00 to Rs. 10.00 per day with effect from 19 April 2001 (Internal memo, 2001). The statistics show that the anticipated increase of membership did take place but not at the levels expected by the library authorities.

There was an annual increase of obtaining library membership at the Colombo Regional Centre (CRC). However, the increase in library membership at regional centres was not up to the expected level (Reader services statistical report - 2006, 2007 and 2008).

In 2004, the Distance Education Modernization Project's (DEMP) Learner Support Team conducted a learner support research survey among learners. The DEMP Survey Report, 2004 highlighted the fact that limited library facilities at the OUSL hindered the academic performance of its learners (DEMP survey report, 2004).

It is imperative to ascertain the reasons for learners not obtaining library membership at the $\mathrm{KRC}$ and MRC. The researcher is of the view that the findings of this study will help improve the services provided by the library which in turn will enable learners to perform better and fulfill their expectations.

\section{Objectives of the study}

- To investigate the reasons why learners use/do not use the borrowing facility in the KRC and MRC.

- To ascertain the information seeking behavior of the non-users of the KRC and MRC.

- To establish the reasons that influence the variables for the usage of the library service. 


\section{Student Support Services}

The Student Support Services (SSS) comprise a cluster of facilities and activities that are intended to make the learning process easier and more interesting for distance learners. SSS in ODL serve as the interface between the institution and the learner.

The support services refer to any service other than the course material that an institution provides to its distance learners to realize the instructional objectives of the course. These services play the role of a relay station (Sharma, 1995).

Simpson (2002) defines SSS as all activities beyond the production and delivery of course material that assist in the progress of learners in their studies.

Tait (2002, pp. 288) presents a more complete definition.

"The range of services both for individuals and for students in groups which complement the course material or learning resources, that are uniform for all learners, and which are often perceived as the major offering of institutions using open and distance learning".

According to Kember \& Dekkers (1987), SSS can be divided into two: academic support; and administrative support. Academic support refers to any assistance provided for helping the learners to understand the learning package, giving feedback on assignments, advising and counselling etc. Administrative support is defined as the promotion and provision of course information, enrolment information or the provision of a first point of contact in assisting learners to interpret and negotiate administrative requirements of the institution. According to Lekamge et.al. (1999) the main support services provided at all centres can be grouped into three main classes such as Academic, Administrative and other services. Other support services refer to library, dormitory, canteen, telephone, postal and banking facilities etc.

Many researchers have studied the role, activities, and importance of SSS YVenkaiah (1994), Chaudhary (1995), Despande (1995), Sharma (1995), Rao (1995) - as cited in Krishore et. al., (1998), Lekamge et al. (1999), Power et.al (2000)\}. These researchers have emphasized the development of SSS as a 3-tier mechanism of core facilities at the headquarters, sufficient facilities at regional centres and moderate facilities at study centres. SSS at each level therefore, have their own 
specific duties to facilitate learning by providing adequate and appropriate resources, and networking facilities to serve distance education at different levels. The basic objective is to link the institution with its distance learners.

Accordingly the OUSL offers support services through 4 regional and 22 study centres. The OUSL regional/study centres are managed by Assistant Directors who work under the supervision of the Director of the Regional Education Services (RES) who is based at the main university.

\section{Library support services}

Library services are one of the most important aspects of SSS in ODL. The basic assumption is that distance learners should be provided a service equals the services available for learners on campus. The ARCL Guidelines for Extended Campus Library Services has emphasized this notion.

"The parent institution is responsible for providing support which ... extended community equitable with that provided to the on-campus community..." (Caballero, 1998).

All regional and study centres of the OUSL have libraries which have holdings that consist of printed and audio-visual material including OUSL course material. Many of the centre libraries provide free internet access to all learners. The CRC library has a well equipped library which is located in the main campus at Nawala. Approximately 5000 material are available at each regional library. However, libraries at the study centres have inadequate resources: basic reference material; OUSL course material; past question papers; general reading material; facilities for using audio and video material are all very limited.

Learners who are registered in any of the regional centres can access the resources and services available at the main library such as the reference material collection, photocopying, accessing the Internet via the Virtual Resource Centre (VRC) and viewing audio-visual material in the Audio Visual Resource Centre (AVRC). The book borrowing facility is restricted to the members of the main library and the KRC and MRC learners who are in level 3 and above. However, a learner who is automatically registered in any centre in the country is permitted to become a member of the main library if the learner agrees to confirm to 
the rules and regulations imposed. Learners have to pay a refundable membership fee of Rs.500.00 to make use of the borrowing facility. Two books may be borrowed for a period of two weeks and a fine of Rs.10.00 per day is charged for overdue books.

\section{The conceptual framework of the study}

Reviewing the literature the researcher identified the following variables that may have an impact on the usage of the library services of the centre libraries by distance learners:

$\mathrm{V} 1=$ Awareness of the library services available for learners.

$\mathrm{V} 2=$ Resources available at centre libraries.

V3 = Personal problems and responsibilities of distance learners.

V4 $=$ Distance between learner's residence and regional centre.

The terms used were the 'library user' and 'library support services'. The diagrammatic representation of this conceptual framework is illustrated in Figure 2.
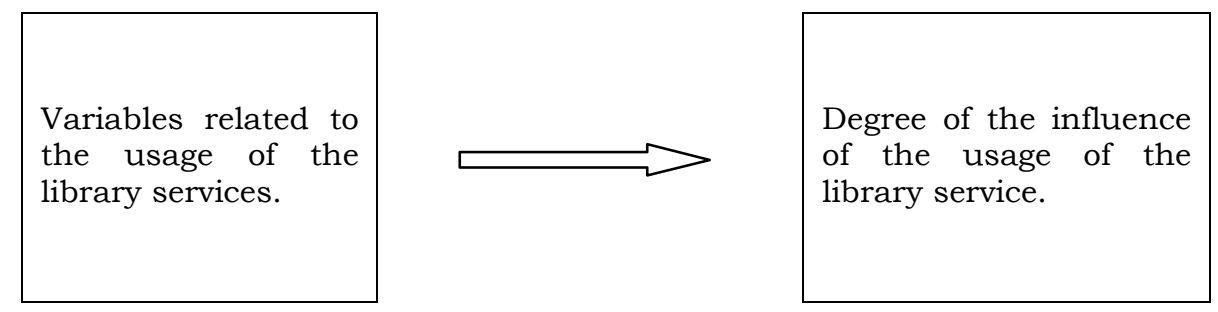

Figure 2: correlation between variables and services

\section{Methodology of the study}

The survey research method which is categorized under descriptive methodology has often been used as a method to access service quality and user satisfaction as it helps to evaluate services (Banwell \& Graham, 2004). The quantitative method was used in this study as the study focuses on investigation and evaluation of the support given to the distance learners of the OUSL. The main research instrument was a questionnaire but archival data on membership was also used. 
The questionnaire consisted of five sections.

- Demographic information

- Membership/non-membership information,

- Reasons for using/not using the borrowing facility,

- Personal responsibilities

- Awareness of the services

\section{Limitations of the study}

The research study was limited to learners who were registered in 2008 for the diploma, undergraduate and postgraduate courses (level 3 and above) conducted by four faculties at the KRC and MRC.

\section{Sample of the study}

Table No. 3 shows that the total number of registered learners for the diploma and degree courses for all the programmes (level 3 and above), for the year 2008 was 1633 in KRC and 599 in MRC. A total of 407 made up of 207 users and 200 non-users from the two regional centres, belonging to four faculties were selected for this study. Of this, 107 from KRC and 100 from MRC were selected as the user sample.

Every 15 th learner from the KRC sample and every $5^{\text {th }}$ learner from the MRC sample was selected to get a sample of 100 to ascertain whether the learners were aware of the services provide and the reasons for not using such services.

Table 2: Users and non-users by Regional Centre

\begin{tabular}{|l|l|l|l|c|}
\hline \multirow{2}{*}{ Faculty } & \multicolumn{3}{|l|}{ Kandy } & Matara \\
\cline { 2 - 5 } & users & non users & users & non users \\
\hline HSS & 38 & 469 & 45 & 79 \\
\hline Education & 18 & 300 & 7 & 139 \\
\hline Engineering & 23 & 114 & 18 & 10 \\
\hline Natural Science & 28 & 643 & 30 & 271 \\
\hline Total & 107 & 1526 & 100 & 499 \\
\hline
\end{tabular}

Source: Registration data and user data 


\section{Data collection}

The questionnaires were posted to learners and a total number of 177 responded. 92 learners (46\%) from KRC and 85 learners (42\%) from MRC responded (See Table 3).

Table 3: Response rate

\begin{tabular}{|l|l|l|l|}
\hline Centre & $\begin{array}{l}\text { No. of } \\
\text { questionnaires } \\
\text { sent }\end{array}$ & Total Responded & \% \\
\hline KRC & 207 & 92 & 46 \\
\hline MRC & 200 & 85 & 42 \\
\hline
\end{tabular}

\section{Findings}

\section{Characteristics of the respondents}

Out of 177 respondents $52.5 \%$ of them were from $\mathrm{KRC}$ and $47.5 \%$ were from MRC. The age groups of the respondents are illustrated in Table 4.

Table 4: Age Group of the sample

\begin{tabular}{|l|l|}
\hline Age Group & Percentage \\
\hline $21-30$, & $78 \%$ \\
\hline $31-40$ & $13 \%$ \\
\hline $41-50$, & $4 \%$ \\
\hline Below 20 & less than 3\% \\
\hline Above 50 & $2.5 \%$ \\
\hline
\end{tabular}

$52 \%$ of the respondents were females and $48 \%$ were males. Of the 31 married respondents $61 \%$ of them had children. The majority of the respondents were living $20 \mathrm{~km}$ or more from the centre $(53 \% \mathrm{KRC}, 60 \%$ $\mathrm{MRC}$ ). $49 \%$ of the respondents ( $44 \mathrm{KRC}, 42 \mathrm{MRC}$ ) were members of the library while $51 \%$ (49 KRC, $42 \mathrm{MRC}$ ) were non-members.

\section{Reasons for using borrowing facility}

A total of 86 library members were surveyed. 39\% (comprising 14) from $\mathrm{KRC}$ and $48 \%$ (comprising 15) from MRC stated that the reason for obtaining library membership was to "to find information to write assignments". They also said that they borrowed books to improve their knowledge of the subjects they were studying. The other reasons given by them were "additional reading material are required to pass the exam" (32\% $\mathrm{KRC}, 61 \% \mathrm{MRC})$ and "it is difficult to obtain good results at 
the final exam without referring books given in the reference list" (25\% KRC, 19\% MRC).

\section{Reasons for not using the borrowing facility}

The researcher also analyzed the characteristics of the non members to ascertain whether there were any personal restrictions that may have prevented them from using the borrowing facility.

Out of 91 non-members 22 (24\%) of them were above 30 years and employed. Out of the 22 employed respondents, $6(27 \%)$ of them were males and married and 4 of them have children.

All the others (69) were unemployed, unmarried and were in the age group 21-30. Out of 69 unemployed learners, 31 of them were females $(45 \%)$ and rest of them (38) were males (55\%). $3 \%$ of them have said that although they have the time to visit the library and use the services they have not become members of the library.

Further analysis shows that there are significant variations in the reasons for not using the library borrowing facility and these are given in Table 5.

Table 5: Barriers to the service

\begin{tabular}{|l|l|l|}
\hline Reasons for not using the service & $\begin{array}{l}\text { \% of the affected } \\
\text { learners }\end{array}$ \\
\cline { 2 - 3 } & KRC & MRC \\
\hline 1. No time for extra reading & $27 \%$ & $26 \%$ \\
\hline $\begin{array}{l}\text { 2.Non availability of relevant material at centre library/ } \\
\text { resources relevant to my subject area are not available }\end{array}$ & $28 \%$ & $37 \%$ \\
\hline 3.Distance between residence and centre library & $38 \%$ & $21 \%$ \\
\hline 4. There is inadequate space allocated in the MRC library & - & $30 \%$ \\
\hline 5. Two weeks loan period is not enough & $31 \%$ & - \\
\hline $\begin{array}{l}\text { 6. It is difficult to visit the library every two weeks to } \\
\text { borrow or return books }\end{array}$ & $4 \%$ & $3 \%$ \\
\hline 7. It is difficult to pay 500 rupees & - & $3 \%$ \\
\hline
\end{tabular}

"Non availability of relevant material at the centre library" was the main reason indicated by the majority of MRC learners while $38 \%$ of KRC learners indicated "distance" as the main barrier (Table 5). Further analysis indicated that $18 \%$ of non-members who followed the LLB and Bachelor of Technology programmes stated that the non 
availability of material relevant for their level of programmes at their centre libraries as the main barrier.

"Non availability of material" was rated as third reason by $28 \%$ of KRC learners while $26 \%$ of MRC learners indicated "Non availability of time" as the third reason. 21\% of MRC learners indicated "distance" as the fourth reason. $31 \%$ of $\mathrm{KRC}$ learners have stated that it is difficult for them to visit the library every two weeks to borrow or return books as they were living more than $30 \mathrm{~km}$ away from the centre. It was revealed that $30 \%$ of MRC learners (second highest) have indicated "space to study in the library" as a problem at the MRC library.

\section{Information seeking behavior}

The findings reveal that $36 \%$ of $\mathrm{KRC}$ and $60 \%$ of MRC learners have stated that they use other libraries to find material for their studies as the centre libraries do not have the relevant material. The most popular libraries for those who have registered for the Social Sciences and LLB programmes are the D S Senanayake Memorial Library and the Court Complex library in Kandy. Further, LLB students indicated that they used the personal libraries of well known lawyers to find relevant information as the centre library does not have the required information.

The Matara Pubic Library and the Richard Pathirana Library in Galle were the most popular libraries used by the MRC learners. The reasons given by $70 \%$ of $\mathrm{KRC}$ and $56 \%$ of MRC learners for visiting other libraries were:

- conveniently located (public libraries)

- availability of great number of general books and

- flexible borrowing facilities (more than two books for a period of more than two weeks).

\section{Awareness of the facility}

Most learners were made aware of the borrowing facility "from their friend/s" (61\% of KRC and $45 \%$ of MRC learners). While $25 \%$ of MRC learners had come to know of the borrowing facility from the 'library leaflet' given to them at their registration. $3 \%$ of the learners were influenced by the library staff. 
Only two learners from KRC had not known about the availability of the service at their centre library.

\section{Influence of variables to the usage}

The four variables used in this study are

$\mathrm{V} 1=$ Awareness of the library services available for learners.

$\mathrm{V} 2=$ Resources available at centre libraries.

V3 = Personal problems and responsibilities of distance learners.

V4 $=$ Distance between learner's residence and regional centre.

The "non availability of resources" (V2) at both centre libraries (28\% of $\mathrm{KRC}$ and $37 \%$ of MRC learners) was the most pronounced variable for not using the regional library centres - Figure 3.

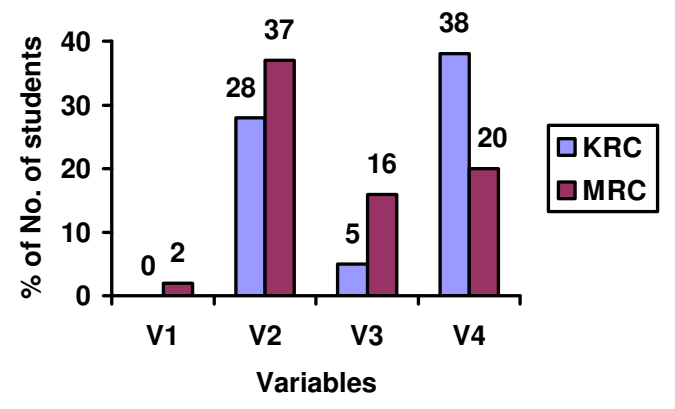

Figure 3: Influence of variables to the usage of the library service

The second most affected variable was "Distance to the centre from home" (V4). It had affected 38\% of KRC and $20 \%$ of MRC learners. The reason given by both $\mathrm{KRC}$ learners (45\%) and MRC learners (21\%) was that "distance" was the main barrier to the usage of the library service. $16 \%$ of MRC learners and $5 \%$ of KRC learners stated that personal problems were the barrier to their usage of library facilities at their respective regional centres. Only $2 \%$ of MRC learners stated that they were unaware of the library facilities at their regional centres. 


\section{Discussion and Recommendation}

The findings indicated that distance learners prefer to refer to other reading material in addition to the course material in order to successfully complete their studies. However, this study reveals that the majority of distance learners at both centres do not use the library facilities as anticipated by the university.

Out of the four variables (V1-V4 in Figure 3), the "non availability of resources at centre libraries" (28\% of KRC and $37 \%$ of MRC learners) was the most prominent variable for not obtaining the membership at the regional centre library. As a result learners had to use the facilities offered by other libraries.

The library should ensure the availability of multiple copies of the required reading lists and adequate numbers of core texts in the centre libraries. Evans, 2003, cited in Kishore (1998) suggested that books chosen by librarians are better used by the distance learners than those selected by academics. In order to facilitate this process, greater co-operation is needed between the academics and the librarians. In this situation, librarians have to play an active role in selecting books based on their professional judgments. In the OUSL at present the role of the librarian in book selection is very minimal.

Hindle (1977) in his report "Developing an acquisition system for a university library" proposes a system in which departments are responsible for the development of research material, while library staff control the provision of teaching material.

Therefore, it would be advisable to take steps to change the existing collection development policy at centre libraries in order to encourage distance learners to engage in self-study using centre libraries more productively.

In order to increase learners' productivity, the following issues that influence the usage of libraries and its services should be addressed: purchasing, stocks management, indexing, extending the lending period and opening hours, space, environment and other library facilities and the provision of relevant books to meet diverse learner needs.

In addition, the allocation of adequate financial resources for centre libraries for the ordering of multiple copies of books, journals and 
audio-visual material is crucial in order to improve the services at the centre libraries.

The second prominent variable was "distance" between the centre and the learner's residence. Most KRC learners were living more than $30 \mathrm{kms}$ away from the centre. As a result "distance" has affected the usage of the borrowing facility as learners have difficulty in visiting the centre library every two weeks to borrow or return library books. Most learners found the "two weeks loan period" inadequate. Because of the great distance between the centre library and their residences, learners found it difficult to visit the library at two week intervals.

In addition, 31\% of MRC learners have indicated that "space" available at the MRC library is limited and that too is an obstacle. Even though this problem is not directly connected to the usage of the borrowing facility, it could affect the regular use of the reference library facilities. Therefore it is necessary to pay attention to expanding the MRC library and increasing the seating facility.

It is apparent that centre libraries do not fulfill the distance learners' requirements and therefore there is a tendency to visit other libraries. These libraries are conveniently located, have a diverse collection which caters to the all the learner's needs: course work reading as well as leisure reading.

The public libraries also play a prominent role in provision of information to most persons in the community as these libraries are conveniently located. Therefore distance learners use public library facilities.

It is worthwhile implementing a reciprocal borrowing scheme that enables learners and staff of any one university to use the facilities of any other participatory library. This will be a great service especially for distance learners who have difficulty in accessing the resources in the center libraries.

It could be concluded that personal problems, responsibilities and awareness of the facilities were not obstacles for the usage of library facilities because a majority of respondents were unmarried and living with parents and they were aware about the facility. 
Most learners said that it was their friends who informed them of the availability of the library facilities. "From their friend" was the preferred source for most learners. Although all except two learners from KRC had been made aware of the library facilities available not all of them made use of these facilities. Being aware of the library facilities available does not automatically mean that those who are aware make optimum use of the facilities available.

In conclusion the following recommendations are proposed:

1. To develop the collection development policy

2. To order multiple copies of reading material, media and e-resources (level-wise) in all centre libraries keeping in mind the requirements of distance learners.

3. Establish strong links between the library and the different faculties so that the library would be kept informed of the needs of each faculty to meet these needs.

4. To implement a reciprocal borrowing scheme for OUSL distance learners by the sharing of material among the regional centres, main library and other university or special libraries such as Teacher Training College Libraries.

5. To develop online library facilities and services through the OUSL library website and make learners aware of these facilities.

6. To extend the lending period for a period of one month.

7. To strengthen the facilities at the MRC library and make it a conducive environment for studying

8. To conduct awareness/orientation programmes by the centre library staff to inform distance learners about the library facilities available (online and offline). 


\section{References}

Banwell, L. \& Graham, C. (2004). "User and user study methodology", a JUBILEE report. Information Research. 9, 2, 250-266.

Caballero, C. (1998). "Thousands still shoeless: developing library services in support of distance education a case study". Journal of Library Services for Distance Education, 1, 2, 1096-2123. Available online at www.westga.edu/jlsde.

Chaudhary, T. (1995). Distance education systems-student support services. Journal of Distance Education. 1, 1, 56-74.

DEMP: survey report of the Learner support team (2004). The Open University of Sri Lanka capacity Enhancement programme. Available online at www.depp. $1 \mathrm{k} / \mathrm{demp} . \mathrm{php}$.

Despande, C. (1995). Management of SSS, single mode Distance Education institutions in India, New Delhi: Association of Indian Universities.

Evans, B. (2003) In. Nanda, R. (2001). Support services for distance learners: a case study. Journal of Distance Education VIII, 1, 83-91.

Gunasekera, D. (2000). A comparative study of the library usage of students engage in distance education with special reference to the Open University of Sri Lanka and NIE. Unpublished MA Thesis. University of Colombo.

Gupta, P. L. \& Gupta, K. (1999). Student Support Services: Back Bone of Distance Education, Journal of Distance Education 6, 7, 428-440.

Hindle, M. (1977). Developing an acquisition system for a university library, Library Review, 26, 2, 106-126.

Internal memo dated 19th .04 .2001 , sent to KRC and MRC regional libraries.

Kamlesh, S. (1995). Student support services. Higher education at a distance. Sanchar, New Delhi: Publishing House.

Kember, D. \& Dekkers, J. (1987). The role of study centres for academic support in distance education. Distance Education. 8, 1, 4-17.

Kishore, S (1998). Student support and quality indicators in distance learning. Indian journal of Open Learning. 7, 2, 205-12. 
Lekamge, G. D., Ranawaka, G., Gunaratne, K. A. R. D. \& Jayananda, R. (1999). Student satisfaction with OUSL support services, OUSL Journal 2, 80-92.

PGDDE course materials - (ESP 1124) Student support system in distance education (2007). Faculty of Education. Nawala: The Open University of Sri Lanka.

Power, C (2000). Quality in distance education, in performance indicators in distance higher education, Aravali, New Delhi.

Reader services statistical report (2006). Library: The Open University of Sri Lanka, (unpublished report).

Reader services statistical report (2007). Library: The Open University of Sri Lanka, (unpublished report).

Reader services statistical report (2008). Library: The Open University of Sri Lanka, (unpublished report).

Sharma, K. (1995). Student support services for distance learners. a paper presented at VIII Annual conference of AAOU on Structure and Management of Open Learning System. 17 June, 1995. New Delhi.

Simpson, O. (2002). Supporting students in online. open and distance learning. London: Kogan page.

Rao, S (1995) In. Nanda, R. (2001). Support services for distance learners: a case study. Journal of Distance Education VIII, 1,.83-91.

Tait, A. (2002). Planning student support for open and distance learning. Open Learning. 15, 3, 287-99.

Venkaiah, S.K. (1994). Student support services in correspondence/distance education in India: a historical perspectives, Journal of Distance Education VI, I, 66-83. 